\title{
Difference in levels of SARS-CoV-2 S1 and S2 subunits- and nucleocapsid protein-reactive SIgM/lgM, IgG and SIgA/IgA antibodies in human milk
}

\author{
Veronique Demers-Mathieu $\mathbb{C}^{1,2} \cdot$ Dung M. Do ${ }^{1} \cdot$ Gabrielle B. Mathijssen ${ }^{1} \cdot$ David A. Sela $\mathbb{C}^{2} \cdot$ Antti Seppo $^{3}$. \\ Kirsi M. Järvinen ${ }^{3} \cdot$ Elena Medo $^{1}$
}

Received: 7 May 2020 / Revised: 3 August 2020 / Accepted: 25 August 2020 / Published online: 1 September 2020

(c) The Author(s), under exclusive licence to Springer Nature America, Inc. 2020

\begin{abstract}
Objective This study evaluated the presence and the levels of antibodies reactive to SARS-CoV-2 S1 and S2 subunits (S1 + S2), and nucleocapsid protein.

Study design The levels of SARS-CoV-2 S1 + S2- and nucleocapsid-reactive SIgM/IgM, IgG and SIgA/IgA were measured in human milk samples from 41 women during the COVID-19 pandemic (2020-HM) and from 16 women 2 years prior to the outbreak (2018-HM).

Results SARS-CoV-2 S1 + S2-reactive SIgA/IgA, SIgM/IgM and IgG were detected in 97.6\%, $68.3 \%$ and 58.5\% in human milk whereas nucleocapsid-reactive antibodies were detected in $56.4 \%, 87.2 \%$ and $46.2 \%$, respectively. S1 + S2-reactive $\mathrm{IgG}$ was higher in milk from women that had symptoms of viral respiratory infection(s) during the last year than in milk from women without symptom. S1 + S2- and nucleocapsid-reactive IgG were higher in the 2020-HM group compared to the 2018-HM group.

Conclusions The presence of SARS-CoV-2-reactive antibodies in human milk could provide passive immunity to breastfed infants and protect them against COVID-19 diseases.
\end{abstract}

\section{Introduction}

SARS-CoV-2 is the novel coronavirus discovered in 2019 (2019-nCoV) that is responsible for the severe acute respiratory syndrome (SARS) pandemic. The coronavirus disease 2019 (COVID-19) was first observed in China. SARS-CoV-2 is responsible for pandemic-level infections

Supplementary information The online version of this article (https:// doi.org/10.1038/s41372-020-00805-w) contains supplementary material, which is available to authorized users.

$\triangle$ Veronique Demers-Mathieu

vdemers-m@medolac.com

1 Department of Neonatal Immunology and Microbiology, Medolac Laboratories A Public Benefit Corporation, Boulder City, NV, USA

2 Department of Food Science, University of Massachusetts Amherst, Amherst, MA, USA

3 Department of Pediatrics, Pediatric Allergy/Immunology, University of Rochester, Medical Center, Rochester, NY, USA globally, including the United States [1]. To induce COVID19 , the spike 1 (S1) subunit attaches to angiotensinconverting enzyme-2 (ACE-2) receptors on the cellular surface of the human respiratory tract [2]. After binding to ACE-2, the spike 2 (S2) subunit fuses the viral particle to the host cell membrane and releases its RNA into the cell, initiating viral replication [3]. High concentrations of viral copies induce host cell lysis and the spread of infectious particles. During the infection, the immune response is activated to produce antibodies by plasma cells (activated B cells) specific to spike proteins (or other viral structural proteins) from SARS-CoV-2. Antibodies specific to S1 or S2 could neutralize and block the attachment and fusion of SARS-CoV-2 to the host cell, before its replication within the lungs and other tissue, including the gastrointestinal tract [4]. Cleavage of the spike protein is an essential step for SARS infection [5]. Antibodies that bind to the spike protein interfere with this cleavage, inhibiting the fusion and the entry of SARS-CoV-2 into the host cell. Therefore, neutralizing antibodies play an important role in viral clearance. The production of these antibodies specific to $\mathrm{S} 1$ or $\mathrm{S} 2$ could help to protect against future COVID-19 infection. 
Infection by or exposure to SARS-CoV-2 could result in the production of secretory $\operatorname{IgA}(\mathrm{SIgA}), \operatorname{Ig} \mathrm{A}$, secretory $\operatorname{IgM}$ (SIgM)/IgM and IgG antibodies specific to SARS-CoV-2 in human milk. A recent study found that milk from a woman diagnosed positive for COVID-19 (SARS-CoV-2 RNA was initially detected in nasopharyngeal but not in serum or breast milk samples) was positive for SARS-CoV-2-specific IgG and negative for IgM on day 8 and day 24 after admission [6], but the antigen used for their detection was not reported. The exposure of SARS-CoV (previous human coronavirus causing an endemic disease in 2003, in China) could also produce antibodies cross-reactive to SARS-CoV-2 that may be protective against COVID-19, as recent studies have demonstrated a genetic similarity between multiple proteins [7]. Among 45 epitopes on SARS-CoV-2 and SARS-CoV, the nucleocapsid has 22 identical epitopes, S1 has three identical epitopes and S2 has 22 identical epitopes [2]. Antibody reactive to $\mathrm{S}$ protein of $\mathrm{SARS}-\mathrm{CoV}-2$ could provide some protection for the infant from COVID-19 infection, but no evidence has been demonstrated at this moment.

The Center for Disease Control and Prevention recommends that pregnant women are vaccinated with inactivated influenza virus (flu shot) and tetanus-reduced-dose diphtheria and acellular pertussis (Tdap) during the late second or third trimester (27-36 weeks of gestation) to maximize protection against these infectious diseases in infants [8, 9]. Vaccine-derived IgG antibodies are transferred to the fetus via the placenta providing passive immunity against these pathogens [10, 11]. Pathogenspecific antibodies in human milk can also be generated during an infection or after exposure to pathogenic microbes [12]. Our previous study demonstrated the survival of influenza A-specific SIgA/IgA, SIgM/IgM and IgG from human milk in the gastrointestinal tract of preterm infants suggests possible protection against influenza diseases [13]. Vaccination could also modulate the adaptive immune responses by generating nonspecific antibodies, which may improve protection against infectious illnesses [14]. Coronaviruses (CoVs) and influenza viruses (IAVs) share some pathological changes and clinical symptoms in patients after infection [15]. The ligand-binding site of $\mathrm{CoV}$ hemagglutinin-esterase (HE), influenza hemagglutininfusion-esterase (HEF) and a subset of CoV spike protein are adapted to recognize 9-O-acetyl-sialogycans to infect cells [16]. Therefore, human milk could possibly contain cross-reactive antibodies that neutralize other coronaviruses or other viruses, including influenza viruses. This would be beneficial in terms of protecting newborns from a variety of viral pathogens.

In this study, we examined the presence and levels of SIgM/IgM, IgG and SIgA/IgA reactive to both SARS-CoV-2 $\mathrm{S} 1$ and $\mathrm{S} 2$ subunits $(\mathrm{S} 1+\mathrm{S} 2)$ and nucleocapsid protein in human milk collected during the COVID-19 pandemic and 2 years prior to the outbreak. We also compared these antibody levels between vaccinated and unvaccinated mothers as well as between women that had symptoms of viral respiratory infection(s) during the year and women without symptoms. Human milk SARS-CoV-2-reactive antibodies could be used as a potential oral antibody therapy to prevent COVID-19 disease, especially to susceptible individuals, including newborns and immunosuppressed patients.

\section{Materials and methods}

\section{Study design and participants}

The first group of human milk samples (2020-HM) was collected during the COVID-19 pandemic (from 30/02/20 to $03 / 04 / 20$ ). These donors were not asked about their COVID-19 status, specific symptoms related to SARSCoV-2, or if they were exposed to COVID-19 positive individuals. A survey was completed by each mother in the 2020-HM group to determine their vaccination status during pregnancy and if they had symptoms of viral respiratory infection during the last year. No mothers were sick (with any type of infection) during the milk collection. The screening survey did include an opportunity to share general viral symptoms, many of which were COVID-19 related [15]. The second group of human milk samples (2018-HM) was collected from 16 mothers between 06/09/18 and 29/ 11/18, before the COVID-19 pandemic. These human milk samples were used as a control group. All women (from both the 2020-HM and 2018-HM groups) were living in the United States (see demographic description in Tables 1 and 2) and were approved donors through Mothers Milk Cooperative (Boulder City, NV). Written consents to use their milk for research were obtained from those mothers. Milk collection was approved by the institutional review board (IRB00012424) of Medolac Laboratories. The criteria pre-established for inclusion are passing blood tests (negative tests for HIV, HTLV, hepatitis B or C and syphilis), living in the USA, completing a health questionnaire, and no use of specific medications. Mothers, who were smokers or drug users were excluded.

\section{Human milk collection}

Human milk samples (150-250 mL) were collected at home with clean electric breast pumps into sterile plastic containers and stored immediately at $-20^{\circ} \mathrm{C}$ in deep freezers. The breast was cleaned with a wet washcloth (no soap or alcohol) before pumping. Milk samples were frozen and transported in insulated boxes to Medolac Laboratories, where they were kept frozen and stored at $-30{ }^{\circ} \mathrm{C}$ in an industrial freezer until the ELISA measurements. 
Table 1 Demographic description (self-reported) of mothers vaccinated and unvaccinated who donated human milk during the COVID-19 pandemic (from 30/02/20 to 03/04/20, 2020-HM).

\begin{tabular}{lll}
\hline Demographics & Vaccinated $(n=26)$ & Unvaccinated $(n=15)$ \\
\hline Postpartum time $^{\mathrm{a}}$ & $5 \pm 3(2-10)$ & $5 \pm 3(2-11)$ \\
Infant gender, $n$ & 11 males:15 females & 6 males:9 females \\
Influenza vaccine, $n^{\mathrm{b}}$ & 11 & - \\
Tdap vaccine, $n^{\mathrm{b}}$ & 8 & - \\
Influenza and Tdap, $n^{\mathrm{b}}$ & 7 & - \\
Viral symptoms, $n^{\mathrm{c}}$ & 10 & 5 \\
No symptoms, $n$ & 9 & 4 \\
\hline
\end{tabular}

${ }^{\mathrm{a}}$ Data are mean $\pm \mathrm{SD}$.

${ }^{b}$ Women were vaccinated with tetanus-reduced-dose diphtheria and acellular pertussis (Tdap) vaccine and/or inactivated influenza virus (flu) vaccine between the second and third trimester (27-36 weeks of gestation).

${ }^{\mathrm{c}}$ Women had symptoms of viral respiratory infection (cold, fever, respiratory infection, sinus infection, nasal congestion, headaches, sore throat and/or flu-like symptoms) during the last year but no infection during the milk collection. These symptoms were self-reported and could be bacterial, allergies or faulty memory. Few women $(n=13)$ did not answer the question on the symptoms of viral infection during the last year.

Table 2 Demographic description (self-reported) of women who donated human milk during the COVID-19 pandemic (2020-HM, from $30 / 02 / 20$ to $03 / 04 / 20$ ) and 2 years prior to the pandemic (2018-HM, $06 / 09 / 18$ to $29 / 11 / 18$ ).

\begin{tabular}{lll}
\hline Demographics & 2020-HM $(n=41)$ & 2018-HM $(n=16)$ \\
\hline Postpartum time, months $^{\mathrm{a}}$ & $5 \pm 3(2-1)$ & $5 \pm 3(2-10)$ \\
Infant gender, $n$ & 17 males:24 females & 8 males:8 females \\
No vaccine, $n(\%)$ & $15(36.6)$ & $10(63.0)$ \\
${\text { Influenza vaccine, } n(\%)^{\mathrm{b}}}$ & $11(26.8)$ & $3(18.8)$ \\
Tdap vaccine, $n(\%)^{\mathrm{b}}$ & $8(19.5)$ & $2(12.5)$ \\
Influenza and Tdap, $n(\%)^{\mathrm{b}}$ & $7(17.1)$ & $1(6.2)$
\end{tabular}

${ }^{\mathrm{a}}$ Data are mean $\pm \mathrm{SD}$.

${ }^{b}$ Women were vaccinated with tetanus-reduced-dose diphtheria and acellular pertussis (Tdap) vaccine and/or inactivated influenza (flu) vaccine between the second and third trimester (27-36 weeks of gestation).

\section{SARS-CoV-2 S1 + S2- and nucleocapsid-reactive antibodies}

The levels of SARS-CoV-2 S1 $+\mathrm{S} 2$ and nucleocapsidreactive $\mathrm{SIgM} / \mathrm{IgM}, \operatorname{IgG}$ and $\mathrm{SIgA} / \operatorname{Ig} \mathrm{A}$ were determined using ELISAs that were adapted from our previous publications [13, 17-19]. ELISAs were recorded with a microplate reader (SpectraMax iD5, Molecular Devices, Sunnyvale, CA). Raw human milk samples $(n=41)$ were rapidly thawed at $37^{\circ} \mathrm{C}$ in a water bath and centrifuged at $1301 \times g$ for $20 \mathrm{~min}$ at $4{ }^{\circ} \mathrm{C}$. After removing the fat layer, the supernatant was collected, separated into aliquots and stored at $-30{ }^{\circ} \mathrm{C}$ until analyzed. Clear flat-bottom microplates (Nunc MaxiSorp, Thermo Fisher Scientific, Rochester, NY) were coated with $100 \mu \mathrm{L}$ of recombinant SARS-CoV-2 (2019-nCoV) S1 + S2 or nucleocapsid (Sino Biological US Inc., Wayne, PA) at $1 \mu \mathrm{g} / \mathrm{mL}$ in $1 \times$ phosphate-buffered saline $\mathrm{pH}$ 7.4 (PBS, Gibco, Grand Island, NY). Microplates were incubated overnight at $4{ }^{\circ} \mathrm{C}$. After incubation, plates were washed three times using PBS with $0.05 \%$ Tween-20 detergent (PBST) (Thermo Fisher Scientific, Rochester, NY) and $200 \mu \mathrm{L}$ of blocking buffer (PBST with $3 \%$ of bovine serum albumin fraction V (Roche Diagnostic GmbH, Manheim, Germany) was added in all wells for $1 \mathrm{~h}$ at room temperature. Standards were prepared using human milk supernatant with the highest optical density (OD) value for each ELISA. Six different standards were used due to the difference of OD values between the different isotypes (SIgM/IgM vs. IgG vs. SIgA/IgA) and the antigens (S1 + S2 vs. nucleocapsid) (Fig. S1). The standards were selected based on the preliminary data of 12 human milk samples diluted at $10 \times$ for $\mathrm{IgG}$ and $\mathrm{SIgM} / \mathrm{IgM}$ and at $50 \times$ for $\mathrm{SIgA} /$ IgA. The levels of SARS-CoV-2 S1+ S2- and nucleocapsid-reactive antibodies were interpolated from the standard curves generated from the human milk supernatants with the assigned quantity expressed in ELISA units $/ \mathrm{mL}$ (U/ $\mathrm{mL})(10 x$-diluted human milk sample $=200$ arbitrary $\mathrm{U} / \mathrm{mL}$ for $\mathrm{IgG}$ and $\mathrm{IgM}, 50 \times$-diluted milk sample $=62.5$ arbitrary $\mathrm{U} / \mathrm{mL}$ for $\mathrm{SIgA} / \operatorname{Ig} \mathrm{A})$. The standard curves were prepared using the dilution series of the human milk supernatants in blocking buffer that covered a range from $2.5 \times(800 \mathrm{U} / \mathrm{mL})$ to $160 \times(12.5 \mathrm{U} / \mathrm{mL})$ for $\mathrm{SIgM} / \mathrm{IgM}$, from $2.5 \times(800 \mathrm{U} / \mathrm{mL})$ to $80 \times(25 \mathrm{U} / \mathrm{mL})$ for $\mathrm{IgG}$ and from $15.6 \times(200 \mathrm{U} / \mathrm{mL})$ to $500 \times(6.25 \mathrm{U} / \mathrm{mL})$ for $\mathrm{SIgA} / \operatorname{IgA}$. Supernatants of human milk samples were diluted $10 \times$ for SIgM/IgM and $\operatorname{IgG}$, and $50 \times$ for $\mathrm{SIgA} / \operatorname{IgA}$ with a blocking buffer. Before each step (addition of $100 \mu \mathrm{L}$ standards/samples and secondary antibodies at $1 \mu \mathrm{g} / \mathrm{mL}$ ), washing and incubation for $1 \mathrm{~h}$ at room temperature were performed. The detection SARS-CoV-2 S1 + S2- and nucleocapsid-reactive antibodies were goat anti-human IgM mu-chain HRP for SIgM/IgM, goat antihuman gamma-chain HRP for IgG and goat anti-human alpha-chain HRP for SIgA/IgA (Abcam, Cambridge, MA).

\section{Inactivation of SARS-CoV-2 S1 + S2 and nucleocapsid-reactive antibodies}

Diluted $(10 \times$ for $\mathrm{SIgM} / \operatorname{IgM}$ and $\operatorname{IgG}$ and $50 \times$ for $\mathrm{SIgA} / \operatorname{IgA}$ ) milk supernatants were either heated at $100{ }^{\circ} \mathrm{C}$ for $30 \mathrm{~min}$ using an Isotemp (Fisher Scientific, Chino, CA) or nonheated (stored in ice) for $30 \mathrm{~min}$, in triplicate for each condition. SARS-CoV-2 S1+S2- and nucleocapsidreactive $\mathrm{SIgM} / \mathrm{IgM}$, IgG, and $\mathrm{SIgA} / \operatorname{Ig} \mathrm{A}$ were measured with ELISAs as previously described above. 
Fig. 1 Percentage of detected antibodies reactive to $S 1$ and S2 subunits $(\mathbf{S 1}+\mathbf{S 2})$, and nucleocapsid from SARSCoV-2 in human milk collected during the COVID19 pandemic. $\mathrm{S} 1+\mathrm{S} 2$-reactive a secretory $\operatorname{IgM}(\mathrm{SIgM}) / \operatorname{IgM}$, b $\operatorname{IgG}$ and c secretory $\operatorname{IgA}$ (SIgA)/IgA in human milk from 41 women. Nucleocapsidreactive d SIgM/IgM, e IgG and f $\mathrm{SIgA} / \operatorname{Ig} \mathrm{A}$. Milk expression period was from $30 / 02 / 20$ to $03 /$ $04 / 20$ in the United States.
A S1+S2-reactive SlgM/lgM

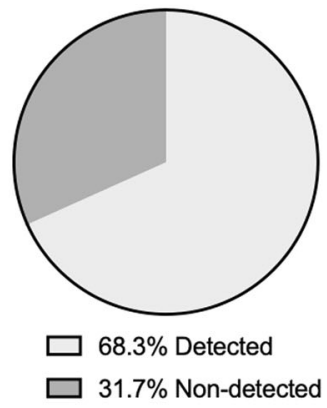

D Nucleocapsid-reactive SlgM/lgM

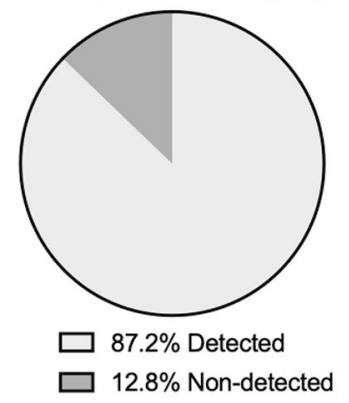

B $\mathrm{S} 1+\mathrm{S} 2$-reactive $\lg \mathrm{G}$

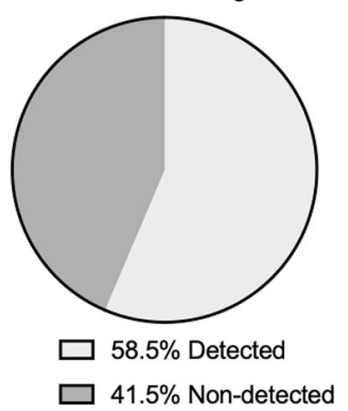

C $S 1+S 2$-reactive $S \lg A / \lg A$

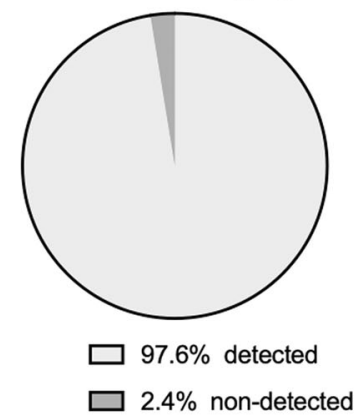

E Nucleocapsid-reactive IgG

F Nucleocapsid-reactive SIgA/lgA
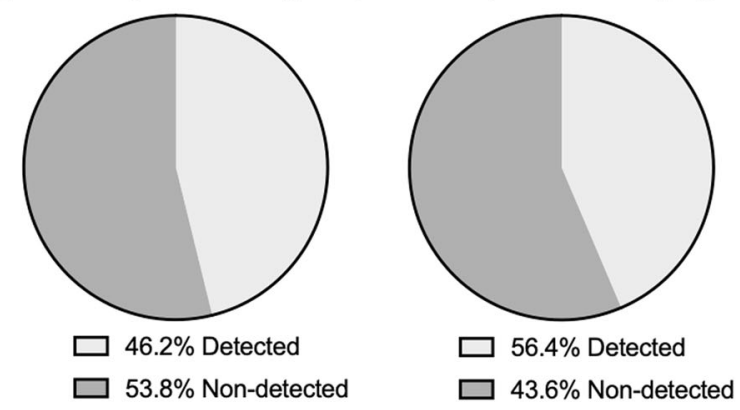

\section{Statistical analysis}

Mann-Whitney test for unpaired sample comparisons of SARS-CoV-2 S1 + S2 and nucleocapsid-reactive antibodies in human milk for vaccinated vs. unvaccinated, influenzavaccinated vs. non-influenza-vaccinated, Tdap-vaccinated vs. non-Tdap-vaccinated, viral symptoms vs. no symptom and 2020-HM group vs. 2018-HM group were applied using GraphPad Prism (version 8). Friedman test (paired samples) followed by Dunn's test (correction for multiple comparisons) was used to compare the levels of isotypes (SIgM/IgM, IgG and SIgA/IgA) of SARS-CoV-2- S1 + S2and nucleocapsid-reactive antibodies in human milk. Linear regression models were used to determine a correlation between SARS-CoV-2 S1 + S2- and nucleocapsid-reactive antibodies. Pearson correlation coefficients $(r)$ were determined when $p<0.1$. The sample size of vaccinated mothers $(n=26)$ and unvaccinated mothers $(n=15)$ was selected based on our previous study [13].

\section{Results}

\section{Maternal demographics}

The maternal demographic details of vaccinated donors and unvaccinated donors in 2020-HM group are presented in Table 1. Maternal demographic details of women in 2020HM group and women in 2018-HM group are described in Table 2. Postpartum time and the ratio of male to female infants were similar between vaccinated and unvaccinated mothers in the 2020-HM and 2018-HM groups. The number of women who had symptoms of viral infection during the last year and the number of women without infection were similar between vaccinated and unvaccinated women.

\section{Presence and levels of SARS-CoV-2 S1 + S2- and nucleocapsid-reactive antibodies in human milk}

The presence of SARS-CoV-2 S1 + S2-reactive SIgM/IgM, $\mathrm{IgG}$, and $\mathrm{SIgA} / \mathrm{IgA}$ was detected in $68.3 \%$ (Fig. 1a), $58.5 \%$ (Fig. 1b), 97.6\% (Fig. 1c) in human milk samples, respectively. The presence of SARS-CoV-2 nucleocapsid-reactive $\mathrm{SIgM} / \operatorname{IgM}, \operatorname{IgG}$ and $\mathrm{SIgA} / \operatorname{IgA}$ was detected in $87.2 \%$ (Fig. 1d), 46.2\% (Fig. 1e) and 56.4\% (Fig. 1f) in human milk samples, respectively. The detection of SIgM/IgM reactive to nucleocapsid in human milk was 1.2-fold higher than $\mathrm{SIgM} / \operatorname{IgM}$ reactive to $\mathrm{S} 1+\mathrm{S} 2$. The detection of $\operatorname{IgG}$ reactive to nucleocapsid was comparable to the $\mathrm{IgG}$ reactive to $\mathrm{S} 1+\mathrm{S} 2$. The detection of $\mathrm{SIgA} / \operatorname{IgA}$ reactive to nucleocapsid in human milk was 1.7 -fold lower compared to $\mathrm{S} I g \mathrm{~A} / \mathrm{Ig} \mathrm{A}$ reactive to $\mathrm{S} 1+\mathrm{S} 2$.

The level of SARS-CoV-2 S1 + S2-reactive SIgA/IgA in human milk was higher than $\mathrm{SIgM} / \mathrm{IgM}$ and $\operatorname{IgG}$ $(p<0.001)$, which were comparable (Fig. 2a). The level of SARS-CoV-2 nucleocapsid-reactive SIgM/IgM was higher than $\operatorname{IgG}(p<0.001)$ and $\operatorname{SIgA} / \operatorname{IgA}(p=0.038)$, whereas SIgA/IgA was higher than $\operatorname{IgG}(p=0.038$, Fig. $2 b)$.

The levels of SARS-CoV-2 S1 + S2- and nucleocapsidreactive $\operatorname{IgG}$ were $4.3-(p=0.013)$ and 2.7-fold $(p=0.041)$ 

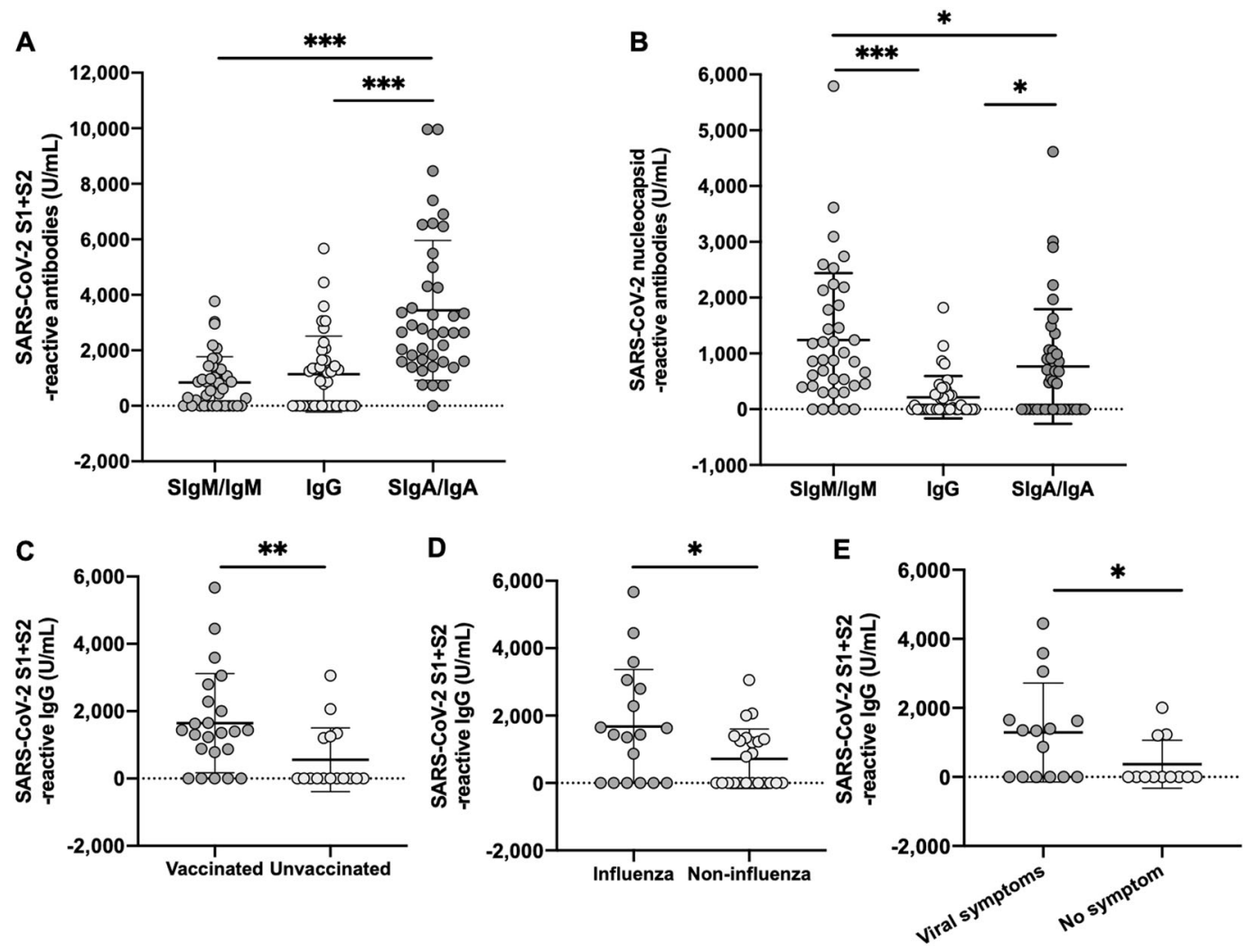

Fig. 2 The levels of SARS-CoV-2-reactive to S1 and S2 subunits $(\mathrm{S1}+\mathrm{S2})$ and nucleocapsid in human milk collected during the COVID-19 pandemic. The levels of a S1 + S2- and b nucleocapsidreactive secretory $\operatorname{IgM}(\mathrm{SIgM}) / \operatorname{IgM}, \operatorname{IgG}$, and secretory $\operatorname{Ig} \mathrm{A}(\mathrm{S} \operatorname{Ig} \mathrm{A}) /$ $\mathrm{IgA}$ in human milk. Values are mean $\pm \mathrm{SD}, n=41$ for women. Asterisks show statistically significant differences between variables $(* * * p<0.001 ; * * p<0.01 ; * p<0.05)$ using the Friedman test followed by Dunn's test (correction for multiple comparisons). c The levels of SARS-CoV-2 S1 + S2-reactive IgG in human milk between vaccinated women $(n=26)$ and unvaccinated women $(n=15)$. $\mathbf{d}$ The level

higher in 2020-HM group (milk collected during COVID19 pandemic) compared to the 2018-HM group (milk collected 2 years ago COVID-19, control group), respectively (Fig. 3b, e). The levels of SIgA/IgA and SIgM/IgM reactive to $\mathrm{S} 1+\mathrm{S} 2$ (Fig. 3a, c) and nucleocapsid (Fig. 3d, f) were comparable between the 2020-HM and 2018-HM groups.

SARS-CoV-2 S1 + S2-reactive SIgA/IgA increased positively with the abundance of S1 + S2-reactive SIgM/IgM $(p=0.050$, Fig. 4a). SARS-CoV-2 S1 + S2-reactive SIgA/ $\operatorname{IgA}$ also tended to increase positively with $\mathrm{S} 1+\mathrm{S} 2$-reactive $\operatorname{IgG}(p=0.058$, Fig. S1C). However, IgG and IgM did not correlate (Fig. S1A). Nucleocapsid-reactive SIgA/IgA increased linearly with $\mathrm{S} 1+\mathrm{S} 2$-reactive $\operatorname{SIgA} / \operatorname{Ig} \mathrm{A}(p=0.005$, Fig. 4b). Nucleocapsid-reactive $\operatorname{SIgA} / \operatorname{IgA}$ also increased positively with nucleocapsid-reactive $\operatorname{SIgM} / \operatorname{IgM}(p=0.005$, Fig. 4c). Nucleocapsid-reactive SIgM/IgM increased linearly with $\mathrm{S} 1+$ S2-reactive SIgM/IgM $(p<0.001$, Fig. $4 d)$. of SARS-CoV-2 S1 + S2-reactive IgG in human milk between influenza-vaccinated mothers $(n=18)$ and non-influenza-vaccinated $(n=23)$. e The levels of SARS-CoV-2 S1 + S2-reactive IgG in human milk between women that had at least one symptom (self-reported) of viral respiratory infection (cold, fever and/or nasal/sinus congestion) $(n=15)$ during the last year and women without symptoms of viral infection $(n=12)$. Values are mean \pm SD. Asterisks show statistically significant differences between variables $(* * p<0.01 ; * p<0.05)$ using the Mann-Whitney test (unpaired nonparametric test).

No correlation was observed for antibodies reactive to S1 + S2- (Fig. S2A) or nucleocapsid (Fig. S2C) between $\mathrm{IgG}$ and $\mathrm{SIgM} / \mathrm{IgM}$. Nucleocapsid-reactive $\mathrm{IgG}$ and $\mathrm{S} 1+$ S2-reactive IgG (Fig. S2B) as well as nucleocapsid-reactive SIgM/IgM and SIgA/IgA (Fig. S2D) did not correlate.

\section{Effect of the type of vaccination during pregnancy on SARS-CoV-2 S1 + S2-reactive antibodies in human milk}

SARS-CoV-2 S1 + S2-reactive IgG from vaccinated women was 2.9 -fold higher than unvaccinated women $(p=$ 0.004, Fig. 2c). S1 + S2-reactive $\operatorname{IgG}$ from influenzavaccinated women was higher than non-influenzavaccinated women $(p=0.031$, Fig. $2 d)$, but did not differ between Tdap-vaccinated and non-Tdap-vaccinated women (data not shown). S1 + S2-reactive $\mathrm{SIgA} / \operatorname{Ig} \mathrm{A}$ or SIgM/IgM were comparable between vaccinated and unvaccinated 

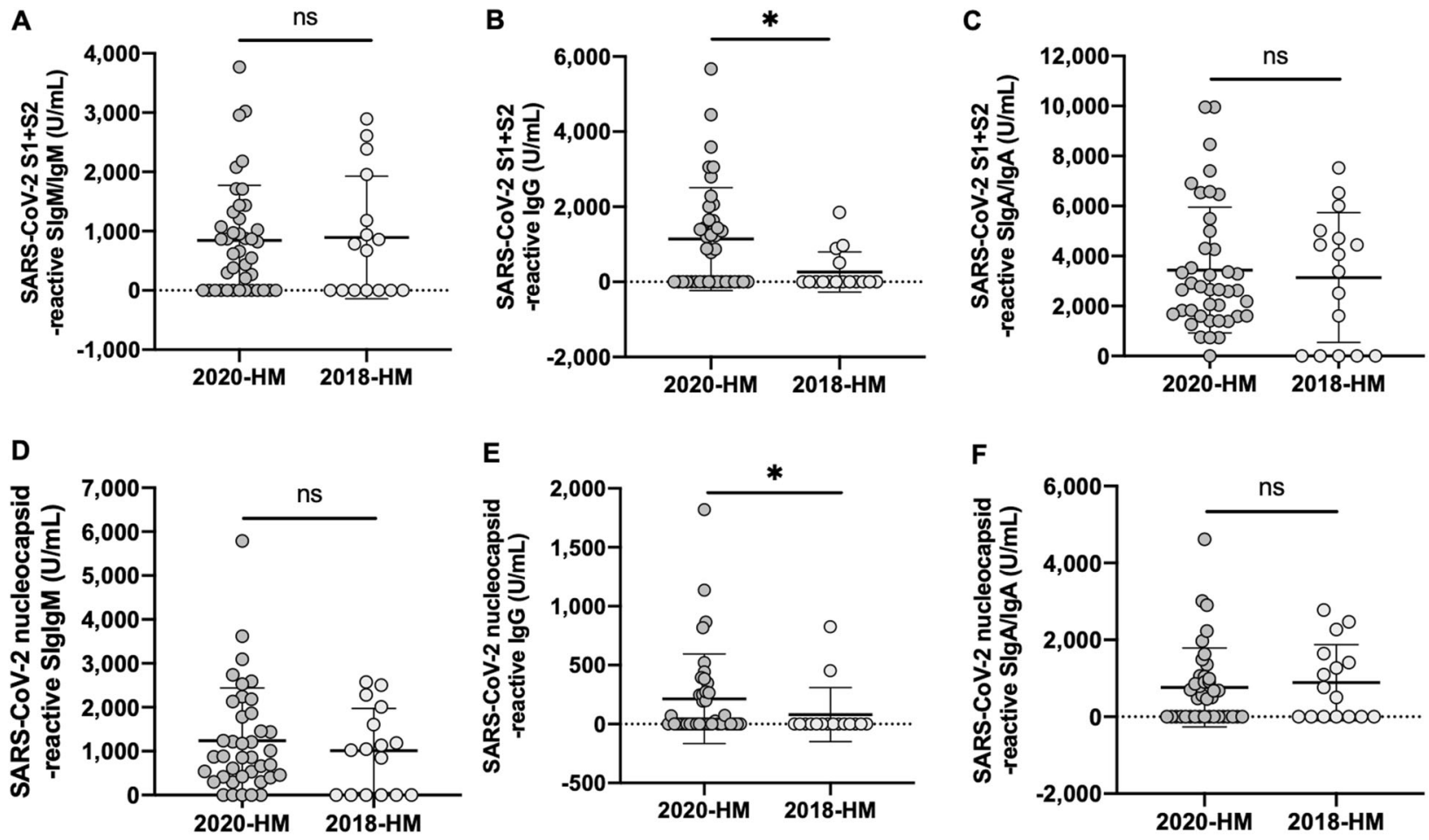

Fig. 3 The levels of antibodies reactive to SARS-CoV-2 S1 and $\mathbf{S 2}$ subunits $(\mathbf{S 1}+\mathbf{S 2})$ and nucleocapsid in human milk collected during the COVID-19 pandemic (2020-HM) and 2 years prior this pandemic (2018-HM). Levels of $\mathrm{S} 1+\mathrm{S} 2$-reactive a secretory IgM $(\mathrm{SIgM}) / \operatorname{IgM}$, b IgG and $\mathbf{c}$ secretory $\operatorname{Ig} \mathrm{A}(\mathrm{SIgA}) / \operatorname{IgA}$ in $2020-\mathrm{HM}$ and 2018-HM. Levels of nucleocapsid-reactive d SIgM/IgM, e IgG and f
SIgA/IgA in 2020-HM and 2018-HM. Values are mean \pm SD, $n=41$ for $2020-\mathrm{HM}$ and $n=16$ for 2018-HM. Asterisks show statistically significant differences between variables $(* p<0.05)$ using the Mann-Whitney test (unpaired nonparametric test). ns Not statistically significant.
Fig. 4 Regression linear between antibodies reactive to SARS-CoV-2 S1 and S2 subunits $(\mathbf{S 1}+\mathbf{S 2})$ and nucleocapsid in human milk collected during the COVID19 pandemic in 41 women. a Positive correlation of $\mathrm{S} 1+$ S2-reactive secretory $\operatorname{IgA}$ $(\mathrm{SIgA}) / \operatorname{IgA}$ and $\mathrm{S} 1+\mathrm{S} 2-$ reactive secretory $\operatorname{IgM}(\mathrm{SIgM}) /$ IgM. b Positive correlation between $\mathrm{S} 1+\mathrm{S} 2$-reactive SIgA/ $\operatorname{IgA}$ and nucleocapsid-reactive SIgA/IgA. c Positive correlation between nucleocapsid-reactive SIgA/IgA and SIgM/IgM. d Positive correlation between nucleocapsid-reactive SIgM/ $\mathrm{IgM}$ and $\mathrm{S} 1+\mathrm{S} 2$-reactive SIgM/IgM. Pearson correlation coefficients $(r)$ were determined when $p<0.1$.
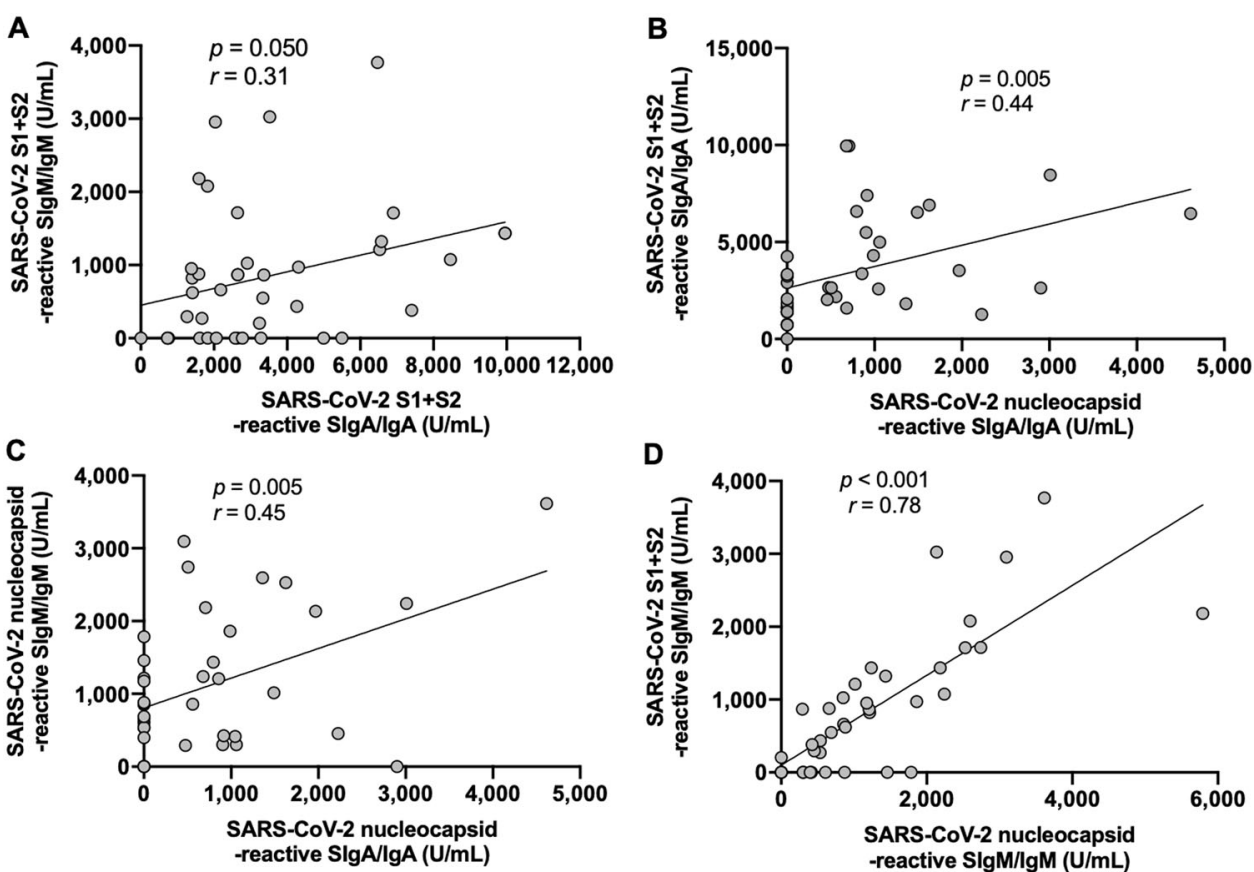

women (Fig. S3A and Fig. S3D), between influenzavaccinated and non-influenza-vaccinated (Fig. S3B, S3E), and between Tdap-vaccinated and non-Tdap-vaccinated (data not shown). The levels of antibodies reactive to nucleocapsid were not affected by the vaccination during pregnancy. 
Effect of viral respiratory infection on SARS-CoV-2 S1 + S2-reactive antibodies in human milk

SARS-CoV-2 S1 + S2-reactive IgG detected in milk from women that had symptoms of a viral respiratory infection (self-reporting diagnosis) during the last year was 3.5-fold higher than women without symptoms in the last year $(p=$ 0.049, Fig. 2e). No difference was found between mothers with symptoms of viral infection and mothers without symptoms of viral infection for $\mathrm{SIgM} / \operatorname{IgM}$ or $\mathrm{SIgA} / \operatorname{Ig} \mathrm{A}$ reactive to $\mathrm{S} 1+\mathrm{S} 2$ (Fig. S3C, Fig. S3F). The levels of antibodies reactive to nucleocapsid were not affected by viral respiratory infection.

\section{Standard curves and inactivation of SARS-CoV-2 S1 + S2- and nucleocapsid-reactive antibodies}

The dose responses for the standard curves SARS-CoV-2 $\mathrm{S} 1+\mathrm{S} 2$ - and nucleocapsid-reactive SIgM/IgM, IgG, SIgA/ IgA using serial dilutions (2-fold) of milk supernatants are illustrated in Fig. S4A-4F. The selection of each standard (supernatant human milk with high OD values) for each ELISA is illustrated in Fig. S1. Binding capacity of SARSCoV-2 S1 + S2- and nucleocapsid-reactive SIgM/IgM, IgG and $\mathrm{SIgA} / \mathrm{IgA}$ from human milk was completely inactivated after heat-treatment at $100{ }^{\circ} \mathrm{C}$ for $30 \mathrm{~min}$ (Fig. S5A-S5B).

\section{Discussion}

The first confirmed case of COVID-19 in the United States was formally diagnosed in January 2020. Confirmed cases rapidly increased to 100 cases on $01 / 03 / 20,9317$ cases on 10/03/20, 9317 cases on 18/03/20 and 105,217 cases on 27/ 03/20 [1]. Antibodies specific or reactive to SARS-CoV-2 in human milk might provide some protection for the infant against COVID-19. However, the levels of SARS-CoV-2 $\mathrm{S} 1+\mathrm{S} 2$ - and nucleocapsid-reactive $\operatorname{IgG}, \mathrm{SIgM} / \operatorname{IgM}$ and $\mathrm{SIg} \mathrm{A} / \operatorname{IgA}$ in human milk are still unknown. In this study, SARS-CoV-2 S1 + S2- and nucleocapsid-reactive SIgM/ IgM, IgG and SIgA/IgA antibodies were detected in a high proportion of human milk samples collected from 30/02/20 to $09 / 04 / 20$. Some mothers may have been exposed or infected with SARS-CoV-2, as asymptomatic infections are common [20]. However, it is possible that the detected antibodies were not only due to SARS-CoV-2 infection, but also due to cross-reactivity with other coronaviruses or other virus families [21-23]. A recent study reported that SARS-CoV-2-specific $\mathrm{CD}^{+}{ }^{+} \mathrm{T}$ cells (from convalescent blood) were detected in 40-60\% of unexposed individuals to COVID-19, suggesting a high degree of cross-reactive and preexisting immunity to SARS-CoV-2 in some, but not all, individuals [23]. Moreover, patients infected with
SARS-CoV produced antibodies reactive to $\mathrm{HCoV}-\mathrm{OC} 43$ [22] whereas patients infected with $\mathrm{HCoV}-\mathrm{OC} 43$ secreted antibodies reactive to SARS-CoV [21]. The presence of cross-reactive antibodies between SARS-CoV and $\mathrm{HCoV}$ OC43 may be possible due to the homology between epitopes on the nucleocapsid (S1 and S2 were not evaluated) [21, 22]. Moreover, the detected SIgM/IgM and SIgA/IgA reactive to SARS-CoV-2 $\mathrm{S} 1+\mathrm{S} 2$ and nucleocapsid could be related to the polyreactive nature of human milk SIgA and SIgM [24-26]. Polyreactive antibodies with low affinity possess an antigen-binding pocket that is more flexible (the ability to bind to several different ligands) than monoreactive antibodies with high affinity [27]. Polyreactive antibodies can accommodate their conformation and recognize various antigens by using different interacting residues [28]. Therefore, polyreactive SIgA and SIgM in human milk could neutralize a higher range of pathogens [24-26], especially considering the high rate of detected antibodies. The levels of antibodies reactive to SARS-CoV$2 \mathrm{~S} 1+\mathrm{S} 2$ were investigated due to the spike proteins' role in inducing infection and its lower genetic similarity with other coronaviruses. The levels of antibodies reactive to nucleocapsid were compared to those with $\mathrm{S} 1+\mathrm{S} 2$ - reactive antibodies. The neutralizing capacity and potential role of human milk antibodies reactive to SARS-CoV-2 S1 + S2 and nucleocapsid in providing passive immunity to infants remains to be seen.

There is only one prior study [6] describing the presence of SARS-CoV-2-specific antibodies in human milk. SARSCoV-2-specific $\operatorname{IgG}$ (on day 8 and 24) was detected in milk from a woman positive for SARS-CoV-2, but the level and specificity of IgG to SARS-CoV-2 were not reported [6]. Another report [29] qualitatively observed the presence of antibodies specific to SARS-CoV (unreported antigen or epitopes) in maternal serum and breast milk collected at 131 days after illness onset in a patient infected with SARS-CoV.

SIgA is the most prevalent isotype in human milk $[18,19]$. We found a similar distribution for SARS-CoV-2 $\mathrm{S} 1+\mathrm{S} 2$-reactive antibodies in mother's milk. Among 41 healthy mothers, a higher number of mothers had S1 + S2reactive $\mathrm{SIgA} / \operatorname{IgA}(97.6 \%)$ compared to $\operatorname{IgG}(58.5 \%)$ or $\mathrm{SIgM} / \operatorname{IgM}(68.3 \%)$ reactive to $\mathrm{S} 1+\mathrm{S} 2$. The level of SARSCoV-2 S1 + S2-reactive SIgA/IgA was higher than $\mathrm{IgM}$ and $\mathrm{IgG}$ reactive to $\mathrm{S} 1+\mathrm{S} 2$. This is likely reflective of the decreasing prevalence of these antibody classes in human milk ( $\operatorname{SIg} \mathrm{A} / \operatorname{Ig} \mathrm{A}>\operatorname{IgG}=\mathrm{SIgM} / \operatorname{IgM})$. The proportion of antibodies in human milk is $\sim 80 \%$ total $\operatorname{IgA}$ $(\sim 73 \% \quad \mathrm{SIg} \mathrm{A} / 27 \% \operatorname{Ig} \mathrm{A}), \sim 15 \%$ total $\operatorname{IgM}(\mathrm{SIgM}+\operatorname{IgM})$ and $\sim 5 \%$ IgG [18].

The detection and levels of nucleocapsid-reactive SIgM/ IgM were higher than $\mathrm{S} 1+$ S2-reactive SIgM/IgM, which could be due to the high polyreactive and/or cross-reactive 
capacity of SIgM to nucleocapsid [24-26]. The detection of $\mathrm{IgG}$ reactive to $\mathrm{S} 1+\mathrm{S} 2$ was lower than $\mathrm{IgG}$ reactive to the nucleocapsid. This result could be due to the high crossreactive capacity of $\operatorname{IgG}$ to the nucleocapsid. These observations are in agreement with the genetic similarity of nucleocapsid protein (22 identical epitopes), which is higher (over $90 \%$ ) compared to $\mathrm{S}$ protein $(76 \%$, the number of identical epitopes was 3 for S1 and 20 for S2) between SARS-CoV-2 and SARS-CoV [2]. In contrast, the detected $\mathrm{SIgA} / \operatorname{IgA}$ reactive to $\mathrm{S} 1+\mathrm{S} 2$ was higher than the nucleocapsid likely due to a high polyreactive and/or crossreactive capacity of $\mathrm{SIgA} / \operatorname{IgA}$ to $\mathrm{S} 1+\mathrm{S} 2$ [24-26]. This observation could be related to the structural similarity of S2 subunits between SARS-CoV-2 and SARS-CoV (or other coronaviruses) $[2,30]$. Previous studies demonstrated that cross-reactive antibodies from convalescent blood to SARS-CoV-2 and other common coronaviruses [21-23]. Our future study will demonstrate the cross-reactive capacity of human milk antibodies to $\mathrm{S} 1+\mathrm{S} 2$ between $\mathrm{HoV}$ OC43 and SARS-CoV-2 as well as their polyreactive capacity to both S1 and S2 (evaluated separately) from SARS-CoV-2. Therefore, the constant region of human milk antibodies may influence their reactivity to SARSCoV-2 S1 + S2 and nucleocapsid.

SARS-CoV-2 S1 + S2-reactive IgG in milk from influenza-vaccinated women during pregnancy was higher than unvaccinated or non-influenza-vaccinated women. Similarly, SARS-CoV-2 S1 + S2-reactive IgG in milk from women that had viral respiratory infection symptoms during the last year was higher than women without infection. These results suggest that SARS-CoV-2 S1 + S2-reactive $\mathrm{IgG}$ in human milk was more associated with the activation of immune responses related to viral diseases or influenza vaccine than SIgM/IgM or SIgA/IgA. This association could be due to the systemic response that a respiratory infection or vaccination induces as $\operatorname{IgG}$ is the most abundant in bloodstream whereas $\mathrm{SIgA} / \operatorname{IgA}$ is more produced in the mucosal secretions (related to enteric pathogens or oral immunization). IgG, which is mostly produced at the end of a new infection, is highly effective at opsonization (facilitating phagocytosis) and activating the complement system, and is often associated with immunity and resistance [31]. Another explanation of these results could be related to the cross-reactive capacity of human milk IgG. IgG produced during the pandemic H1N1 infection were broadly crossreactive against epitopes in the head domain of multiple influenza strains [32]. There are several strains of $\mathrm{CoVs}$ (HCoV-NL63, HCoV-HKUI and HCoV-OC43) and IAVs (H1N1, H5N1, H7N9 and H3N2) that cause seasonal cold and/or respiratory diseases. CoVs and IAVs share some pathological changes and clinical symptoms in patients after infection [15]. The HCoV-OC43 spike and HCoV-HKU1 spike proteins share some functionality (receptor attachment and membrane fusion) with influenza $\mathrm{A} / \mathrm{B}$ hemagglutinin [16]. Human milk IgG might be cross-reactive to CoVs and other viruses, including IAVs. However, more studies are needed to confirm the cross-reactive capacity of human milk antibodies to neutralize SARS-CoV-2 and IAVs.

Among other benefits, mother's milk provides protection against viral respiratory infection, partially due to the transfer of maternal viral pathogen-specific antibodies to the infant. The lacteal lymphatic capillary located exclusively in the intestinal villi of the small intestine is responsible for absorbing lipids, immune surveillance and removal of interstitial fluid. This capillary may absorb and transport human milk antibodies to the respiratory system as its bed connects the gastrointestinal system with the lymphatic and circulatory systems. It could be a possible mechanism for the protection against neonatal respiratory tract infections in infants [33]. Exclusive breastfeeding during the first 6 months of life significantly decreases infant febrile respiratory illnesses [34]. Studies on human milk antibodies specific to respiratory viruses have focused on associations between maternal vaccination during pregnancy and human milk $\operatorname{IgG}, \operatorname{IgM}$ and IgA levels to influenza viruses [35]. This study demonstrated another benefit of influenza-vaccination on maternal antibodies specific to respiratory viruses in human milk. Infants of influenza-vaccinated mothers who were exclusively breastfed in the first 6 months of life had significantly fewer respiratory illness with fever episodes [36]. Jarvinen et al. recently observed that unlike $\operatorname{IgG}$ antibodies, influenza A virus-specific IgA antibody levels in human milk were mostly discordant compared to maternal serum [37]. This observation could be related to the polyreactive properties of $\operatorname{SIgA}$ in human milk compared with IgA in serum.

The first few cases of COVID-19 in the United States were reported during January 2020, but the kinetics of producing strong SARS-CoV-2-specific antibody responses requires at least two weeks. Thus, some women may have been exposed to SARS-CoV-2 before the milk collection (from 30/02/20 to 04/09/20) and their human milk may contain antibodies specific to SARS-CoV-2. A limitation of this study was the absence of information on whether the mothers were previously infected with or exposed to SARS$\mathrm{CoV}-2$. We did not detect viral RNA from SARS-CoV-2 in all human milk samples using real-time RT-qPCR (data not shown), which suggests the mothers were likely not infected with SARS-CoV-2 during the milk collection.

\section{Conclusion}

In summary, this study revealed that antibodies reactive to SARS-CoV-2 S1 + S2 and nucleocapsid were detected in a high proportion in human milk. The constant region of human milk antibodies may influence their reactivity to 
SARS-CoV-2 S1 + S2 and nucleocapsid. The SIgA/IgA and SIgM/IgM responses appeared to be nonspecific to SARS-CoV-2 $\mathrm{S} 1+\mathrm{S} 2$ and nucleocapsid and therefore SARS-CoV-2-specific IgA and IgM were not measurable with the current assays. Their high relative abundance and proportion in mother's milk samples are due to their crossreactive and polyreactive properties of human milk secretory antibodies. The IgG responses seem distinct between unexposed and exposed women's samples. However, some overlap in the $\operatorname{IgG}$ response was observed between unexposed and exposed women. The relevance of the unexposed women who have SARS-CoV-2-specific IgG response detected in the same range as the exposed women should be evaluated using neutralization assays. The presence of SARS-CoV-2-reactive antibodies in human milk could provide passive immunization to the breastfed infants. There is currently no effective oral antibody therapy for COVID-19 infection. Human milk antibodies with high polyreactive and cross-reactive properties against SARSCoV-2 and other coronaviruses could be useful to neutralize and protect against future coronavirus pandemics, especially in vulnerable populations. The purification of antibodies reactive to SARS-CoV-2 from human milk is needed to evaluate their neutralizing capacity against SARS-CoV-2 using in vitro and in vivo studies.

Acknowledgements We thank all study participants for their valuable contributions.

Funding The authors (VDM, DMD, GBM and ED) disclosed receipt of the financial support from Medolac Laboratories A Public Benefit Corporation for the conduct of the study.

Author contributions VDM conceptualized and designed the study, carried out the analyses and the statistical analysis, drafted the manuscript and approved the final paper as submitted. VDM have primary responsibility for the final content. DMD and GBM carried out some ELISA analyses. EM have obtained the funding acquisition of this study. DMD, GBM, DAS, AS, KMJ and EM provided suggestions for analyses and critically revised the paper and approved the final paper as submitted.

\section{Compliance with ethical standards}

Conflict of interest VDM, DMD, GBM and EM are employees at Medolac Laboratories. DAS is on the scientific advisory board for Medolac Laboratories. AS and KMJ have no conflict of interest to disclose.

Publisher's note Springer Nature remains neutral with regard to jurisdictional claims in published maps and institutional affiliations.

\section{References}

1. Johns Hopkins University \& Medicine. COVID-19 Dashboard by the Center for Systems Science and Engineering (CSSE) at Johns
Hopkins University (JHU). 2020. https://coronavirus.jhu.edu/map. html.

2. Ahmed SF, Quadeer AA, McKay MR. Preliminary identification of potential vaccine targets for the COVID-19 coronavirus (SARS-CoV-2) based on SARS-CoV immunological studies. Viruses 2020;12:254.

3. Fu Y, Cheng Y, Wu Y. Understanding SARS-CoV-2-mediated inflammatory responses: from mechanisms to potential therapeutic tools. Virol Sin. 2020;35:266-71.

4. Sungnak W, Huang N, Bécavin C, Berg M, Queen R, Litvinukova $M$. et al. SARS-CoV-2 entry factors are highly expressed in nasal epithelial cells together with innate immune genes. Nat Med. 2020;26:681-7.

5. Du L, He Y, Zhou Y, Liu S, Zheng BJ, Jiang S. The spike protein of SARS-CoV - a target for vaccine and therapeutic development. Nat Rev Microbiol. 2009;7:226-36.

6. Yu, Y., Xu, J., Li, Y., Hu, Y., \& Li, B. Breast milk-fed infant of COVID-19 pneumonia mother: A case report. Research Square, Preprint. 2020. https://doi.org/10.21203/rs.3.rs-20792/v1.

7. Lu R, Zhao X, Li J, Niu P, Yang B, Wu H, et al. Genomic characterisation and epidemiology of 2019 novel coronavirus: implications for virus origins and receptor binding. Lancet. 2020;395:565-74.

8. Centers for Disease Control and Prevention (CDC). Updated recommendations for use of tetanus toxoid, reduced diphtheria toxoid and acellular pertussis vaccine (Tdap) in pregnant women and persons who have or anticipate having close contact with an infant aged $<12$ months-Advisory Committee on Immunization Practices (ACIP). MMWR Morb Mortal Wkly Rep. 2011;60:1424-6.

9. Centers for Disease Control and Prevention (CDC). Vaccines during and after pregnancy. 2019. https://www.cdc.gov/vaccines/ pregnancy/vacc-during-after.html.

10. Healy CM, Rench MA, Baker CJ. Importance of timing of maternal combined tetanus, diphtheria, and acellular pertussis (Tdap) immunization and protection of young infants. Clin Infect Dis. 2012;56:539-44.

11. Halperin BA, Morris A, Mackinnon-Cameron D, Mutch J, Langley JM, McNeil SA, et al. Kinetics of the antibody response to tetanus-diphtheria-acellular pertussis vaccine in women of childbearing age and postpartum women. Clin Infect Dis. 2019;53:885-92.

12. Raya BA, Srugo I, Kessel A, Peterman M, Bader D, Peri R, et al. The induction of breast milk pertussis specific antibodies following gestational tetanus-diphtheria-acellular pertussis vaccination. Vaccine. 2014;32:5632-7.

13. Demers-Mathieu V, Huston RK, Markell AM, McCulley EA, Martin RL, Dallas DC. Antenatal influenza A-specific IgA, IgM, and IgG antibodies in mother's own breast milk and donor breast milk, and gastric contents and stools from preterm infants. Nutrients. 2019;11:1567.

14. Aaby P, Kollmann TR, Benn CS. Nonspecific effects of neonatal and infant vaccination: public-health, immunological and conceptual challenges. Nat Immunol. 2014;15:895-9.

15. Jiang C, Yao X, Zhao Y, Wu J, Huang P, Pan C, et al. Comparative review of respiratory diseases caused by coronaviruses and influenza A viruses during epidemic season. Microb Infect. 2020;22:236-44.

16. Tortorici MA, Walls AC, Lang Y, Wang C, Li Z, Koerhuis D, et al. Structural basis for human coronavirus attachment to sialic acid receptors. Nat Struct Mol Biol. 2019;26:481-9.

17. Demers-Mathieu V, Underwood MA, Beverly RL, David DC. Survival of immunoglobulins from human milk to preterm infant gastric samples at 1,2 , and $3 \mathrm{~h}$ postprandial. Neonatology. 2018;114:242-50. 
18. Demers-Mathieu V, Underwood MA, Beverly RL, Nielsen SD, Dallas DC. Comparison of human milk immunoglobulin survival during gastric digestion between preterm and term infants. Nutrients. 2018;10:631.

19. Demers-Mathieu V, Huston RK, Markell AM, McCulley EA, Martin RL, Spooner M, et al. Differences in maternal immunoglobulins within mother's own breast milk and donor breast milk and across digestion in preterm infants. Nutrients. 2019;11:920

20. Guan WJ, Ni ZY, Hu Y, Liang WH, Ou CQ, He JX, et al. Clinical characteristics of coronavirus disease 2019 in China. N Engl J Med. 2020;382:1708-20.

21. Patrick DM, Petric M, Skowronski DM, Guasparini R, Booth TF, Krajden, et al. An outbreak of human coronavirus OC43 infection and serological cross-reactivity with SARS coronavirus. Can J Infect Dis Med Microbiol. 2006;17:330-6.

22. Chan KH, Chan JF, Tse H, Chen H, Lau CC, Cai JP, et al. Crossreactive antibodies in convalescent SARS patients' sera against the emerging novel human coronavirus EMC (2012) by both immunofluorescent and neutralizing antibody tests. J Infect. 2013;67:130-40.

23. Grifoni A, Weiskopf D, Ramirez SI, Mateus J, Dan JM, Moderbacher CR, et al. Targets of $\mathrm{T}$ cell responses to SARS-CoV-2 coronavirus in humans with COVID-19 disease and unexposed individuals. Cell. 2020;181:1489-501.e15.

24. Taylor HP, Dimmock NJ. Mechanism of neutralization of influenza virus by secretory $\operatorname{IgA}$ is different from that of monomeric IgA or IgG. J Exp Med. 1985;161:198-209.

25. Stubbe H, Berdoz J, Kraehenbuhl JP, Corthésy B. Polymeric IgA is superior to monomeric $\operatorname{IgA}$ and $\operatorname{IgG}$ carrying the same variable domain in preventing Clostridium difficile toxin A damaging of T84 monolayers. J Immunol. 2000;164:1952-60.

26. Corthsy B. Recombinant secretory immunoglobulin A in passive immunotherapy: linking immunology and biotechnology. Curr Pharm Biotechnol. 2003;4:51-67.
27. Gunti S, Notkins AL. Polyreactive antibodies: function and quantification. J infect Dis. 2015;212:S42-6.

28. Mouquet $\mathrm{H}$, Nussenzweig MC. Polyreactive antibodies in adaptive immune responses to viruses. Cell Mol Life Sci. 2012;69:1435-45.

29. Robertson CA, Lowther SA, Birch T, Tan C, Sorhage F, Stockman L, et al. SARS and pregnancy: a case report. Emerg Infect Dis. 2004;10:345.

30. Walls AC, Park YJ, Tortorici MA, Wall A, McGuire AT, Veesler D. Structure, function, and antigenicity of the SARS-CoV-2 spike glycoprotein. Cell. 2020;181:281-92.e6.

31. Janda A, Bowen A, Greenspan NS, Casadevall A. Ig constant region effects on variable region structure and function. Front Microbiol. 2016;7:22.

32. Wrammert J, Koutsonanos D, Li GM, Edupuganti S, Sui J, Morrissey M, et al. Broadly cross-reactive antibodies dominate the human B cell response against 2009 pandemic H1N1 influenza virus infection. J Exp Med. 2011;208:181-93.

33. Cifarelli V, Eichmann A. The intestinal lymphatic system: functions and metabolic implications. Cell Mol Gastroenterol Hepatol. 2019;7:503-13.

34. Frank NM, Lynch KF, Uusitalo U, Yang J, Lönnrot M, Virtanen $\mathrm{SM}$, et al. The relationship between breastfeeding and reported respiratory and gastrointestinal infection rates in young children. BMC Pediatr. 2019;19:339.

35. Maertens K, De Schutter S, Braeckman T, Baerts L, Van Damme $\mathrm{P}$, De Meester I, et al. Breastfeeding after maternal immunisation during pregnancy: providing immunological protection to the newborn: a review. Vaccine. 2014;32:1786-92.

36. Schlaudecker EP, Steinhoff MC, Omer SB, McNeal MM, Roy E, Arifeen SE, et al. IgA and neutralizing antibodies to influenza a virus in human milk: a randomized trial of antenatal influenza immunization. PLoS ONE. 2013;8:e70867.

37. Jarvinen KM, Wang J, Seppo AE, Zand M. Novel multiplex assay for profiling influenza antibodies in breast milk and serum of mother-infant pairs. F1000Res. 2018;7:1822. 